\title{
ТЕТРА- И ПЕНТАЦИКЛИЧЕСКИЕ УГЛЕВОДОРОДЫ В ОРГАНИЧЕСКОМ ВЕЩЕСТВЕ ГОРЮЧИХ СЛАНЦЕВ
}

\author{
(Представил О. Эйзен)
}

Изучение полициклических насыщенных углеводородов состава $\mathrm{C}_{27}$ и более высокомолекулярных привлекает внимание многих исследователей, работающих в области органической геохимии каустобиолитов. Такие свойства тетра- и пентациклических соединений, как близость к известным биологическим молекулам, специфичность структуры, химическая стабильность, малая вероятность синтеза в значительных количествах абиогенным путем позволяют считать их биологическими «метками», изучение которых даст возможность получить надежную геохимическую информацию. Структурная аналогия реликтовых углеводородов и соединений, свойственных живой природе, позволяет проследить биосинтетическую последовательность преобразования исходной биоорганической молекулы в реликтовый углеводород. Таким образом, реликтовые биомолекулы (хемофоссилии), присутствующие в составе ископаемой органики, представляя собой соединения с унаследованной от живой природы структурой, могут дать однозначную информацию как об исходной биомассе каустобиолитов, так и о путях ее эволюции в различных степенях катагенеза. Исследованию высокомолекулярных насыщенных углеводородов уделяется большое внимание и при изучении химического состава горючих сланцев, так как это дает возможность более обоснованно судить об исходном органическом веществе (OB) горючих сланцев и степени его катагенетической преобразованности.

Как показали более ранние исследования ['], под влиянием электронного удара насыщенные и ненасыщенные тетра- и пентациклические углеводороды претерпевают весьма характерный фрагментарный распад, который может быть использован с целью идентификации индивидуальных соединений в сложных смесях. Во многих случаях, путем сравнения с масс-спектром эталонного образца, соединение неизвестного строения можно отнести к определенному классу, установить место заместителей и расположение двойных связей в циклической системе. Изучение соотношения интенсивностей основных фрагментарных ионов в пентациклических углеводородах ряда гопана дает возможность различать структуры, сохранившие конфигурацию углеродного атома 17 в биомолекулах (транс-сочленение колец Д/E, конфигурация $17 \beta \mathrm{H}$, $21 \beta \mathrm{H})$ и структуры, претерпевшие некоторые изомеризационные превращения (цис-сочленение колец Д/E, конфигурация $17 \alpha \mathrm{H}, 21 \beta \mathrm{H}$ ). Сопоставление интенсивностей осколочных ионов с $m / e .217$ и 218 , образующихся при распаде под влиянием электронного удара тетрацикли-

1 ENSV TA Toimetised. K 31981 
ческих соединений, позволяет решить вопрос о характере сочленения колец С/Д. Транс-сочленение $\frac{m / e 217}{m / e 218}>1$ характерно для биостеранов, цис-сочленение $\frac{m / e 217}{m / e 218}<1$ - для стеранов, обнаруженных в нефтях.

Тетра- и пентациклические углеводороды были изучены в горючих сланцах многих месторождений. Особенно много работ посвящено изучению тетра- и пентациклов в сланце Грин-Ривер $\left[{ }^{1-8}\right]$. В 1965 г. M. Кальвин с сотрудниками $\left[{ }^{2}\right]$ сообщили о проведении идентификации стеранов $\mathrm{C}_{27}, \mathrm{C}_{28}, \mathrm{C}_{29}$ и тритерпана $\mathrm{C}_{30}$ из экстракта сланца ГриіРивер. Идентификация и установление структуры этих соединений проводились с помощью масс-спектрометрии, газожидкостной хроматографии и ИК-спектрофотометрии. С помощью масс-спектров аутентичных образцов структура идентифицированных стеранов и тритерпана $\mathrm{C}_{30}$ была установлена с полной достоверностью. Тритерпан $\mathrm{C}_{30}$ был идентифицирован как гаммацеран. В исследованной фракции сланца ГринРивер тетра- и пентациклические углеводороды различного молекулярного веса и строения были обнаружены в значительных концентрациях. Тетра- и пентациклические соединения, входящие в состав этого сланца, особенно детально былие изучены в [ $\left.{ }^{1}\right]$. Методом хромато-масс-спектрометрии идентифицированы: 5 пентациклических тритерпанов, один из которых - геммарцеран; 11 трициклических терпанов; 7 тетрациклов; холестаны, стигмастаны и эргостаны $5 \alpha$ и $5 \beta$, а также прегнан $5 \alpha$.

Соотношение интенсивностей ионов с $m / e 149$ и 151 в масс-спектрах стеранов позволяет определить конфигурацию колец $A$ и $B$. В случае транс-сочленения колец $A$ и $B$ отношение $\frac{m j e 149}{m / e 151}>1$, при цис-сочленении колец $-\frac{m / e 151}{m / e 149}>1$. Большая часть пентациклических соединений в сланце Грин-Ривер относится к гопанам ряда $17 \alpha \mathrm{H}$. При пиролизе керогена этого сланца образуются тетра- и пентациклические соединения, которые, по данным хромато-масс-спектрометрического анализа, аналогичны стеранам и тритерпанам, идентифицированным в экстрактах этого сланца. В последнее время тетра- и пентациклические соединения изучались и в ряде других сланцев [9]. В мессельском сланце [10] обнаружены 2 серии гопанов: ряд гопанов $\left(\mathrm{C}_{27}-\mathrm{C}_{32}\right)$, конфигурация которых соответствует биологическим гопанам $(17 \beta \mathrm{H}$, $21 \beta \mathrm{H})$, другая серия гопанов $\left(\mathrm{C}_{27}-\mathrm{C}_{31}\right)$ имеет конфигурацию $17 \alpha \mathrm{H}$, $21 \beta$. Последняя серия в живых организмах пока не найдена. На основании изучения большого количества различных осадков в [10] сделан вывод, что гопаны серии $17 \beta \mathrm{H}$, конфигурация которых соответствует исходным биосоединениям, присутствуют в катагенетически мало преобразованных отложениях. Высшие гомологи биологических гопанов обычно присутствуют в виде одного диастереомера при хиральном центре $\mathrm{C}_{22}$. В более зрелых осадках преобладают гопаны серии $17 \alpha \mathrm{H}, 21 \beta \mathrm{H}$, причем в высших гомологах наблюдается смесь $(1: 1)$ двух диастереомеров, отличающихся различной конфигурацией углерода $\mathrm{C}_{22}$. Таким образом, изучение стереохимических особенностей тетра- и пентациклических соединений дает возможность достаточно обоснованно судить о глубине катагенетической преобразованности ОВ горючих сланцев, в которых эти стераны и тритерпаны идентифицированы.

В горючих сланцах месторождений Советского Союза тетра- и пентациклические углеводороды ранее не изучались. В связи с этим нами была поставлена задача идентифицировать тетра- и пентациклические 
Характеристика исследованных сланцев.

\begin{tabular}{|c|c|c|c|c|c|c|c|c|c|c|}
\hline \multirow{2}{*}{ 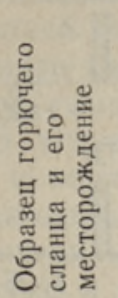 } & \multirow[b]{2}{*}{ 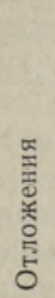 } & \multirow{2}{*}{ 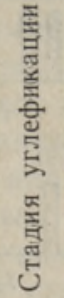 } & \multicolumn{3}{|c|}{$\begin{array}{c}\text { Технический } \\
\text { анализ, вес.\% }\end{array}$} & \multicolumn{3}{|c|}{$\begin{array}{l}\text { Элементарный } \\
\text { анализ, вес.\% }\end{array}$} & \multirow{2}{*}{ 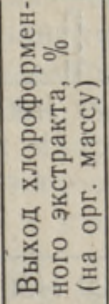 } & \multirow{2}{*}{ 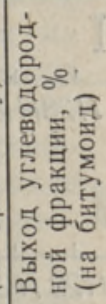 } \\
\hline & & & $\mathrm{W}^{\mathrm{a}}$ & $\mathrm{A}^{\mathrm{c}}$ & $V^{r}$ & $\mathrm{C}^{\mathrm{r}}$ & $\mathrm{H}^{\mathrm{r}}$ & $\begin{array}{l}\tilde{\omega} \\
+ \\
+ \\
\vec{L} \\
+ \\
\dot{b} \\
0\end{array}$ & & \\
\hline
\end{tabular}

Спигас, Лат-

вийская ССР современные

Олеру, Лат-

вийская ССР

$\begin{array}{llllllll}13,00 & 12,48 & 83,85 & 56,60 & 6,90 & 36,50 & 1,9 & 2,0\end{array}$

Тауне, Латвий-

ская ССР сапропели

Ново-Дмитров-

ский, УССР неоген

Байсунский,

Узбек. ССР палеоген

Сузакский,

Узбек. ССР палеоген

Кашпирский, юра

Канадский,

провинция

Альберта

девон

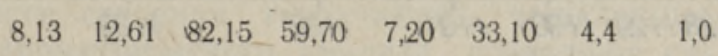

Якутский,

р. Оленек

Болтышский,

\section{УССР}

кембрий

\section{$9,77 \quad 29,60$}

(4) 32

$\begin{array}{llllllll}9,77 & 29,60 & 80,52 & 57,70 & 7,50 & 34,80 & 4,5 & 0,5\end{array}$

$\mathrm{b}_{1}$

$2,14 \quad 68,73 \quad 94,41 \quad 56,20 \quad 6,90 \quad 36,90$

$\mathrm{B}_{3}$

$\begin{array}{llllllll}4,27 & 63,92 & 80,77 & 74,82 & 8,48 & 16,70 & 4,0 & 3.3\end{array}$

$\begin{array}{lllllllll}\mathbf{b}_{3} & 3,33 & 44,21 & 70,78 & 67,51 & 6,20 & 26,21 & 3,8 & 7,6\end{array}$

$\begin{array}{lllllllll}\mathrm{b}_{2} & 3,24 & 46,66 & 76,54 & 64,28 & 6,28 & 29,44 & 0,7 & 12,4\end{array}$

Кукерсит,

Эст. ССР

шахта Кява II ордовик

Кукерсит

(Ленинград-

ская обл.)

ордовик

Б

$\begin{array}{lllllll}0,28 & 89,02 & 37,85 & 61,90 & 5,50 & 32,60 & 2,9\end{array}$

2,4

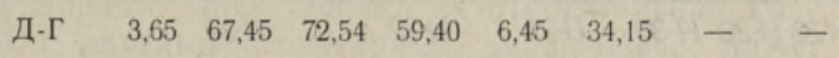

$\begin{array}{llllllllll}\text { палеоген } & \text { Б } & 1,70 & 41,86 & 80,52 & - & - & - & 2,4 & 8,9\end{array}$

Б $\quad \begin{array}{llllllll}1,98 & 48,22 & 88,88 & 62,66 & 7,55 & 29,79 & 0,4 & 4,7\end{array}$

углеводдороды в образцах горючих сланцев некоторых месторождений СССР и установить закономерности их концентрационного распределения в ОВ горючих сланцев различного возраста и степени катагенетической преобразованности.

Для изучения параметров относительного концентрационного распределения тетра- и пентациклов была подобрана коллекция горючих сланцев различного геологического возраста, однородных по морфологическим и петрографическим признакам (таблица). Детальная петрографическая характеристика выбранных для исследования сланцев приведена в ряде работ $\left[{ }^{11-13}\right]$. По предварительной схеме классификации керогена горючих сланцев изученные образцы относятся к классу собственно сапропелитов с коллоальгинитовым и талломоальгинитовым типами керогена по соотношению керогенобразующих и второстепенных компонентов. Для сравнительного анализа закономерностей распределения насыщенных полициклических углеводородов состава $\mathrm{C}_{27}$ и более высокомолекулярных в ОВ различной степени катагенетической преобразованности тетра- и пентациклы были изучены в трех образцах современных сапропелей из озер Латвии [14] и сланце из 


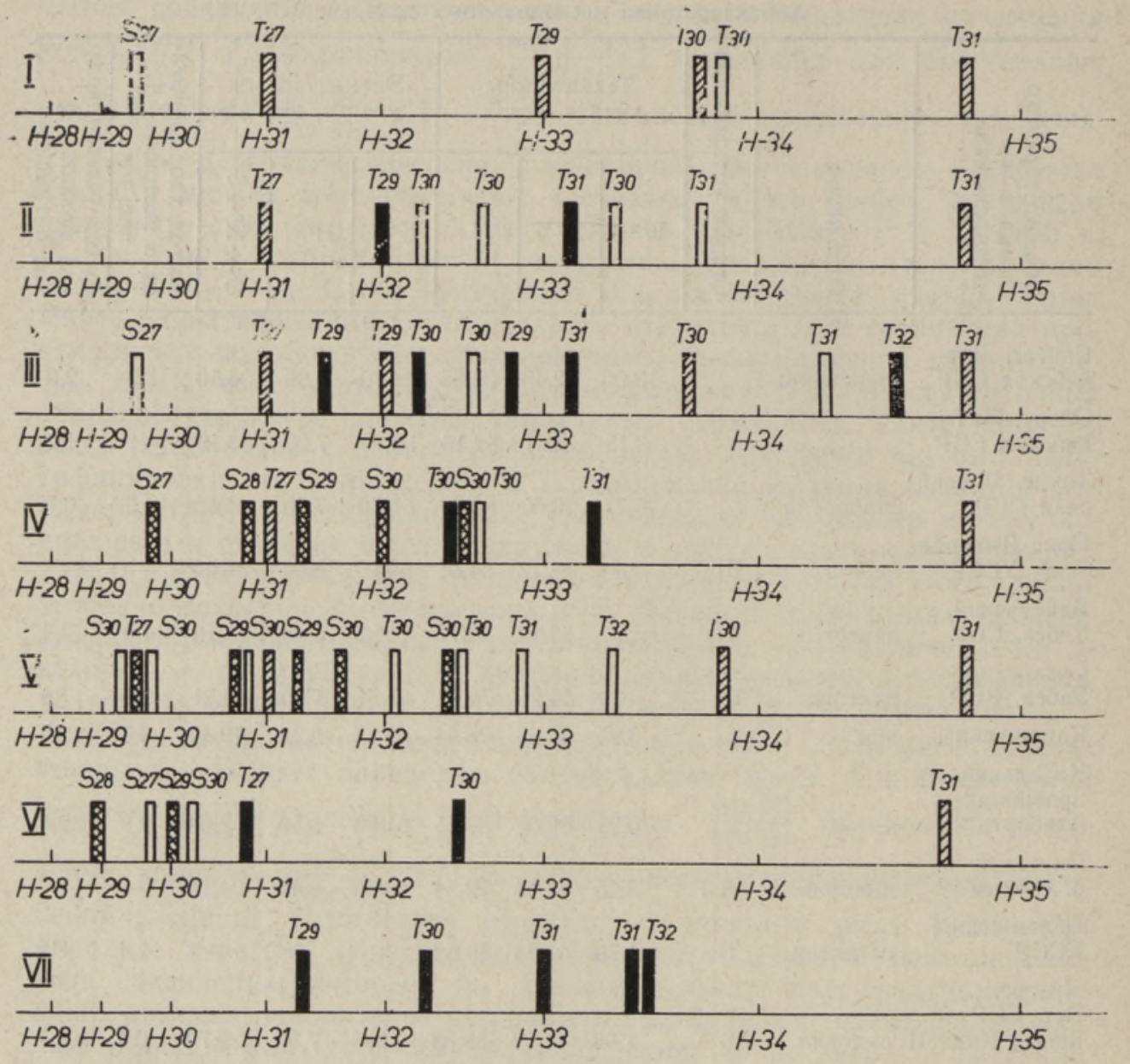

Унифицированные хроматограммы тетра- и пентациклов горючих сланцев различного возраста и степени углефикации. Современные сапропели: I - озера Спигас, II озера Олеру; III - озера Тауне. Горючие сланцы: IV - байсунский (Б), V - сузакский $\left(\mathrm{B}_{3}\right)$, VI - кашпирский $\left(\mathrm{Б}_{2}\right)$, VII - сланец провинции Альберта (Канада). H-28-H-35 - места хроматографического элюирования числом атомов углерода в молекуле; $T_{n}$ - пентациклы с соответствующим числом атомов углерода в молекуле; $S_{n}$ - стераны с соответствующим числом атомов углерода в молекуле.

провинции Альберта (Канада). Методика выделения углеводородной фракции детально описана ранее $\left[{ }^{15-18}\right]$. Изучение состава и распределения тетра- и пентацикланов в выделенной углеводородной фракции проводилось методом хромато-масс-спектрометрии. Для предварительного разделения смеси на индивидуальные углеводороды использовалась капиллярная колонка $l=15 \mu, \varnothing=0,25$ мм. Давление газа-носителя - гелия - 1,4 aT, температура хроматографирования $-290^{\circ} \mathrm{C}$, 
фаза - апьезон L. Ввиду малого количества пробы для анализа использовалась вся углеводородная фракция без отделения части, кипящей при низкой температуре. Масс-спектры регистрировали на хромато-масс-спектрометре ЛКБ-2091 (энергия ионизации электронов 70 э $B$, температура ионного источника $\left.-250^{\circ}\right)$.

В углеводородной фракции всех изученных современных сапропелей и горючих сланцев идентифицированы тетра- и пентациклические углеводороды с различным молекулярным весом, строением и с́тереохимическими особенностями (рисунок). Идентифицированные насыщенные и ненасыщенные стерановые углеводороды выкипают в основном в интервале кипения $\boldsymbol{H}$-парафинов $\mathrm{C}_{27}-\mathrm{C}_{30}$. Лишь температура кипения отдельных гомологов тетрациклических соединений $\mathrm{C}_{27}-\mathrm{C}_{29}$, обнаруженных в сланцах, выше, чем $н$-парафина $\mathrm{C}_{32}$.

Стереохимические особенности строения тетрациклов, выявленные с помощью хромато-масс-спектрометрического анализа, позволяют судить о степени катагенетической преобразованности исследованных сланцев. Например, в сузакском сланце (Узбекская ССР) наряду со стеранами, показывающими в масс-спектрах отношение ионов $\frac{m / e 217}{m / e 218}>1$, обнаружены тетрациклы, в которых интенсивность иона c $m / e 218$ выше интенсивности иона с $m / e$ 217. Бо́льшая интенсивность иона с $m / e 218$ свидетельствует о цис-сочленении $C / Д$ колец, характерном для строения стерановых углеводородов, идентифицированных в нефтях. Следовательно, на определенной стадии катагенетической превращенности в ОВ горючих сланцев наблюдается появление углеводородов нефтяного типа. В горючем сланце кашпирского месторождения $\left(J, Б_{2}\right)$, так же как и в среднеазиатских сланцах, идентифицированы углеводороды стеранового типа. Однако их относительная концентрация по сравнению с другими структурами значительно ниже, чем в сузакском и байсунском сланцах. Интервал их выкипания ограничивается температурным интервалом кипения $\boldsymbol{H}$-парафинов $\boldsymbol{H}$ - $\mathrm{C}_{29}-\mathcal{H}-\mathrm{C}_{30}$. Все идентифицированные в кашпирском сланце стерановые углеводороды характеризуются транс-сочленением циклов $C / Д \frac{m / e 217}{m / e 218}>1$, которое свойственно биологически синтезированным стерановым углеводородным соединениям. Таким образом, несмотря на более древний геологический возраст кашпирского сланца, степень его химической преобразованности меньше, чем эоценовых сланцев сузакского и байсунского месторождений. Меньшая преобразованность ОВ кашпирского сланца отражена и в более низкой стадии углефикации $\left(\mathrm{Б}_{2}\right)$ по сравнению с рассмотренными среднеазиатскими сланцами $\left(\mathrm{Б}_{3}\right)$. Наряду с тетрациклическими углеводородами в ОВ горючих сланцев идентифицированы пентациклические углеводороды различного строения. Во всех изученных сланцах обнаружены ненасыщенные пентациклы, тритерпаны с конфигурацией $17 \beta \mathrm{H}, 21 \beta \mathrm{H}$ (биогопаны) и $17 \alpha \mathrm{H}, 21 \beta \mathrm{H}$ (нефтяные гопаны). Отличительная особенность девонского сланца из провинции Альберта (Канада) - наличие в ОВ этого образца только стереохимически преобразованных тритерпанов ряда $17 \alpha \mathrm{H}, 21 \beta \mathrm{H}$ (нефтяные гопаны). Следует подчеркнуть, что в ОВ гумусового типа наличие только стереохимически преобразованных тритерпанов с циссочленением колец Д/E отмечается в клареновых углях стадии углефикации $\Gamma$ (градация катагенеза $\mathrm{MK}_{2}$ ).

Сравнительный анализ пентациклических соединений талломоальгинитовых сланцев буроугольной стадий углефикации (болтышский сланец, кукерситы из Эстонской ССР и Ленинградской области) пока- 
зал различия в стереохимическом строении тритерпанов в образцах различного геологического возраста. Так, в болтышском сланце и в кукерситах идентифицирован гопан $\mathrm{C}_{31}(17 \alpha \mathrm{H}, 21 \beta \mathrm{H})$. Однако в углеводородной фракции кукерсита (Ленинградская область) в области элюирования гопана $\mathrm{C}_{31}(17 \alpha \mathrm{H}, 21 \beta \mathrm{H})$ наблюдается 2 пика, массспектры которых оказались одинаковыми. Это дает основание предположить, что пики принадлежат двум диастереомерам по $\mathrm{C}_{22}(R$ и $S)$. Так как биологически синтезированные гопаны характеризуются наличием только одного диастереомера, появление указанных диастереомеров гопана $\mathrm{C}_{31}$, отличающихся различной конфигурацией углерода $\mathrm{C}_{22}$, свидетельствует о большей химической преобразованности ОВ кукерсита, чем болтышского сланца.

Таким образом, процесс преобразования исходных биоорганических молекул в нефтяные реликты сопровождается не только структурными превращениями (элиминированием функциональных групп, насыщением двойных связей, реакциями лерераспределения водорода), но и изменением пространственной конфигурации этих молекул.

Реликтовый характер рассматриваемых углеводородов позволяет высказать некоторые соображения и оे характере исходного вещества горючих сланцев. В эоценовом сланце Болтышского месторождения основная доля индивидуальных углеводородов, кипящих при температуре выше $450^{\circ}$, приходится на пентациклические углеводороды. Стерановые углеводороды присутствуют в меньших концентрациях, чем тритерпаны. Аналогичные соотношения между относительными концентрациями тетра- и пентациклических соединений наблюдаются и в углеводородной фракции современных сапропелей Латвии (озера Тауне, Олеру). Вероятно, правомерно предположение, что ОВ типа сапропелей могло послужить исходным для болтышского сланца. Для кукерситов, кипящих выше $450^{\circ}$, в углеводородной фракции которых отмечается заметное возрастание доли тетрациклических соединений, исходное вещество было качественно иным. Микроскопическое исследование шлифов, показавшее, что сапропель не мог быть исходным веществом для образования кукерсита, подтверждает это предположение [19].

Таким образом, проведенное хромато-масс-спектрометрическое исследование тетра- и пентациклических соединений в ОВ горючих сланцев показало, что сланцы различного возраста и стадии углефикации отличаются по обнаруженным в них стеранам и тритерпанам. Выявленные стереохимические закономерности в строении углеводородов ряда стеранов и гопанов позволили установить, что изменение стереохимии представляет важнейшую особенность преобразования исходного биоматериала в недрах земли, приводящую к образованию горючих ископаемых. Изучение структурных и стереохимических особенностей гопановых и стерановых углеводородов дает возможность установить стадию преобразования ОВ горючих сланцев, в которой изменяется структура и стереохимия биосинтезированных углеводородов и фиксируются характерные для нефтей соединения - гопаны и стераны с цис-сочленением колец (C/Д и Д/E соответственно), диастереомеры гопана $\mathrm{C}_{31}$ и более высокомолекулярные. Следует подчеркнуть, что обнаруженные особенности стереохимического строения тетра- и пентациклических соединений можно рассматривать как параметры степени относительной катагенетической преобразованности горючих сланцев. Диастереомеры гопана $\mathrm{C}_{31}$, стераны с цис-сочленением C/Д циклов, гопаны ряда $17 \alpha \mathrm{H}, 21 \beta \mathrm{H}$ могли появиться только в результате изомеризационных превращений биомолекул в процессе катаге- 
неза, поскольку в исходном ОВ стераны и гопаны характеризуются транс-сочленением колец. Соотношение между стереохимически неизмененными стеранами и гопанами, а также тетра- и пентациклами этих гомологических рядов, претерпевшими изомеризационные преобразования в процессе катагенеза, может быть использовано в качестве геохимического критерия степени катагенетической преобразованности ОВ каустобиолитов (в частности, горючих сланцев).

\section{Л ИТ Е РА Т У Р А}

1. G a 11 e gos, E. J. Identification of new steranes, terpanes and branched paraffins in Green River shale by combined capillary gas chromatography and mass spectrometry. - Analyt. Chem., 1971, v. 43, N 10, p. 1151-1160.

2. Burling a me, A. L., H a ug, P., B e ls ky, J., C a lvi n, M. Occurrence of biogenic steranes and pentacyclic triterpanes in an eocene shale $(52 \mathrm{ml}$. years) and in Early Precambrian shale (2.7 bil. years). - Proc. Nat. Acad. Sci. USA, 1965, v. 54, p. $1406-1411$.

3. Anderson, P. C.. G a rdner, P. M., Whitehead, E. V., Anders. D. E., Robinson, W. E. The isolation of steranes from Green River oil shale. Geochim. Cosmochim. Acta, 1969, v. 33, N 8, p. 1304-1307.

4. Murphy Sister M. T. J., M c Cormick, A., Eglint on, G. Perhydro- $\beta$-carotene in the Green River shale, - Science, 1967, v. 157. p. 1040-1042.

5. Henderson, W., Wollrab, V., Eglinton. G. Identification of steranes and triterpanes from a geological source by capillary gas liquid chromatography. Chem. Commun., 1968, p. $710-712$.

6. Hills, J. R., Whitehead, E. V., Anders, D. E., Comm ins, J. J., Robinson, W. E. An optically active triterpane, ganimacerane in Green River Colorado oilshale bitumen. - Chem. Commun., 1966, p. 752-754.

7. Hills, J. R., S m ith, G. W., Wh it ehe ad, E. V. Hydrocarbons from fossil fuels and their relationship with living organisms. - J. Inst. Petrol., 1970, v. 56, N 549 , p. $127-137$.

8. Balogh, B., Wilson, D. M., Christianson, P., Burlingame, A. L. $17 a(\mathrm{H})$ hopane identified in oil shale of Green River formation (eocene) by carbon-13 NMR. - Nature, 1973, v. 242, p. 603-605.

9. K imble, B. J., Maxwell, J. R., Philp, R. P., Eglinton, G., Albrecht, P., Ensm inger, A., A prin o, P., O uris s o n, G. Tri- and tetraterpenoid hydrocarbons in the Messel oil shale. - Geochim. Cosmochim. Acta, 1974, v. 38, N 7, p. $1165-1181$.

10. Ensminger, A., van Dorsselaer, A., Shyckerelle, Ch.; Albrecht, P., Ourisson, G. Pentacyclic triterpenes of the hopane type as ubiquitous geochemical markers, their origin and significance. - In: Advances in Organic Geochemistry 1973. Paris, 1974 , p. 245-260.

11. Гин збург А. И. Органическое вещество петрографических типов горючих сланцев (на примере некоторых месторождений СССР). - Литология и полез. ископ., 1969 , № 4, с. $39-52$.

12. Котлуков В. А., Гин н бу рг А. И. Сланценосные формации СССР. - В кн.: Угленосные формации и их генезис. М., 1973, с. 61-69.

13. Формации горючих сланцев. Таллин, 1973.

14. Б ракш Н. Н. Сапропелевые отложения и пути нх использования. Рига, 1971

15. Сергиенко С. Р., Михновская А. А. Исследование группового состава высокомолекулярных углеводородов нефти при помощи адсорбционной хроматографии. - В кн.: Академия наук СССР. Труды комиссии по аналити ческой химии. 1955 , т. 6 , № 1, с. $162-165$.

16. Бедов Ю. А., Пустильникова С. Д., Ратникова А. Р., Петров А. А Получение нефтяных углеводородов из жирных кислот термокаталитическим путем. - Нефтехим., 1962, т. 2, № 3, с. 313-317.

17. Солодков В. Г., Камьянов В. Ф., Драгунская В. С. Изопреноидные углеводороды в нефтях и конденсатах Западной Туркменни. - Изв. АH Туркмен. ССР, сер. фнз.-техн., хим. и геол. наук, 1974, № 4, с. $76-84$.

18. Гуляева Н. Д., А рефьев О. А., Соколов В. Л., Петров А. А. Закономерности распределения нормальных и изопреноидных алканов в углях различной стадии метаморфизма. - Хим. тверд. топл., 1976, № 1, с. 105-1:10.

19. Р а удсе п п Х. Т. О генезисе горючего сланца-кукерсита. - В кн.: Горючие сланцы (геохим. и литолог.). Тез. докл. I республ. совещания, 1975, с. 9-14. 
N. GULJAJEVA, O. AREFJEV, A. PETROV

\section{POLEVKIVI ORGAANILISE AINE TETRA- JA PENTATSUKLILISED SUSIVESINIKUD}

On esitatud mitmesuguse vanusega ja mitmesugusel katageneesiastmel olevate põlevkivicrimite orgaanilises aines leiduvate tetra- ja pentatsükliliste süsivesinike uurimise tulemused. Kromatomassispektromeetrilise analüüsi teel leitud steraani- ja hopaanirea süsivesinike struktuuri ja stereokeemia seaduspärasused kinnitavad stereokeemiliste muutuste suurt tähtsust fossiliseerumisprotsessides.

N. GULYAEVA, O. AREFYEV, A. PETROV

\section{TETRA- AND PENTACYCLIC HYDROCARBONS IN THE ORGANIC MATTER OF OIL SHALES}

The results of studies are presented of tetra- and pentacycles in the organic matter of oil shales of different age and degree of catagenetic transformation. The structural and stereochemical regularities in the hydrocarbon structure of a series of steranes and hopanes revealed by chromatographic mass spectrometric analysis permitted to state that a change of stereochemistry is the most important feature of the initial material transformation leading to the formation of oil minerals. 